University of Nebraska - Lincoln

DigitalCommons@University of Nebraska - Lincoln

\title{
The Impact of Wire Stent Fabrication Technique on the Performance of Stent Placement
}

\author{
Shijia Zhao \\ University of Nebraska-Lincoln \\ Xiangyi (Cheryl) Liu \\ Dassault Systemes Simulia Corporation \\ Linxia Gu \\ University of Nebraska-Lincoln, gul@fit.edu
}

Follow this and additional works at: https://digitalcommons.unl.edu/mechengfacpub

Part of the Mechanical Engineering Commons

Zhao, Shijia; Liu, Xiangyi (Cheryl); and Gu, Linxia, "The Impact of Wire Stent Fabrication Technique on the Performance of Stent Placement" (2012). Mechanical \& Materials Engineering Faculty Publications. 61. https://digitalcommons.unl.edu/mechengfacpub/61

This Article is brought to you for free and open access by the Mechanical \& Materials Engineering, Department of at DigitalCommons@University of Nebraska - Lincoln. It has been accepted for inclusion in Mechanical \& Materials Engineering Faculty Publications by an authorized administrator of DigitalCommons@University of Nebraska Lincoln. 


\section{The Impact of Wire Stent Fabrication Technique on the Performance of Stent Placement}

Department of Mechanical \&

Materials Engineering,

University of Nebraska-Lincoln,

Lincoln, NE, 68588-0656

Xiangyi (Cheryl) Liu

Dassault Systemes Simulia Corporation, 166 Valley Street,

Providence, RI, 02909- 2499

Linxia Gu'
Department of Mechanical \&
Materials Engineering,
University of Nebraska-Lincoln,
Lincoln, NE, 68588-0656;
Nebraska Center for Materials and Nanoscience,
Lincoln, NE, 68588-0656

\section{Introduction}

Self-expandable wire stents are either braided or welded together [1]. Specifically, braided wire stents are manufactured in various crisscross patterns and materials; if the intersection points of Nitinol wires are welded together at the nominal dimension, they become welded wire stents. There is a paucity of numerical models regarding the performance of wire stents in a stenosed artery, even though the finite element method has demonstrated its effectiveness in evaluating the performance of laser-cut stents during their deployment [2-5]. This may be due to the difficulty in developing braided wire stent models or the complexity of wire interactions. Kim et al. [6,7] simulated the mechanical behavior of self-expandable braided stents and investigated the effect of number of wires and braiding angle on the radial strength of stent. De Beule et al. [8] optimized the braided wire stent geometry to reduce foreshortening by $20 \%$ while maintaining the radial stiffness. Additional investigations of the wire stent-artery interaction are needed to understand the outcomes after wire stent deployment and improve the stent design accordingly.

In this study, a braided wire stent was developed using Abaqus/Explicit 6.10 (Dassault Systèmes Simulia Corp., Providence, RI, USA), and its performance in a moderate stenosed artery was investigated and compared with its welded form.

\section{Material and Methods}

The braided Nitinol self-expandable Expander ${ }^{\mathrm{TM}}$ stent (Medicorp S. A., Villers les Nancy, France) was studied. It was braided with 20 Nitinol wires in a helical form with pitch angle of $30 \mathrm{deg}$. The wire diameter is $0.14 \mathrm{~mm}$. The nominal dimension of the

${ }^{1}$ Corresponding author. e-mail: lgu2@unl.edu

Manuscript received August 15, 2011; final manuscript received December 20, 2011; published online March 12, 2012. Assoc. Editor: Danny Bluestein. stent is $10 \mathrm{~mm}$ in diameter, and $36 \mathrm{~mm}$ in length. The 3D model of braided wire stent is demonstrated in Fig. 1. The stent was meshed with 6400 linear beam elements (B31), which account for large axial strains as well as transverse shear strains. A welded wire version of the same configuration was created for the comparative study. The distinct features of these two types of stents are depicted in Fig. 2.

The nonlinear superelasticity of Nitinol was modeled as a predefined user material with nine critical parameters to define the stress induced phase transformation between the Austenite and Martensite phases [9]. Initially, the Nitinol exhibits Austenite's crystal structure with Young's modulus of $46.728 \mathrm{GPa}$ and a Poisson's ratio of 0.33 . When loaded such that the stent is crimped into the sheath, the Nitinol material transforms from Austenite to Martensite. The transformation is initiated from the stress of 358.2 $\mathrm{MPa}$ and completed by the stress value of $437.8 \mathrm{MPa}$ into a complete Martensite phase with a Young's modulus of 25.199 GPa and Poisson's ratio of 0.33 . The Martensite begins to revert to Austenite once the stress is decreased to $124.25 \mathrm{MPa}$, such as when the sheath is removed. The original Austenite phase will be totally recovered when the stress is further reduced to $17.75 \mathrm{MPa}$. The transformation strain is $4.26 \%$. The material parameters were implemented in the Abaqus user material subroutine (VUMAT).

Both braided and welded wire stent were crimped into a sheath through uniform radial displacement boundary conditions, and then confined by the sheath (Fig. 3). The deployment of the stent was achieved by applying a linear ramping velocity on the sheath to remove it axially. The sheath is defined by a surface obtained by extending a circle section along the axial direction, which was meshed with 38 four-node surface elements with reduced integration (SFM3D4R).

After the stent was crimped inside a $3.4 \mathrm{~mm}$ in diameter sheath, it was then delivered into the target lesion. The artery has an inner diameter of $9 \mathrm{~mm}$, wall thickness of $1 \mathrm{~mm}$ and length of $70 \mathrm{~mm}$. 


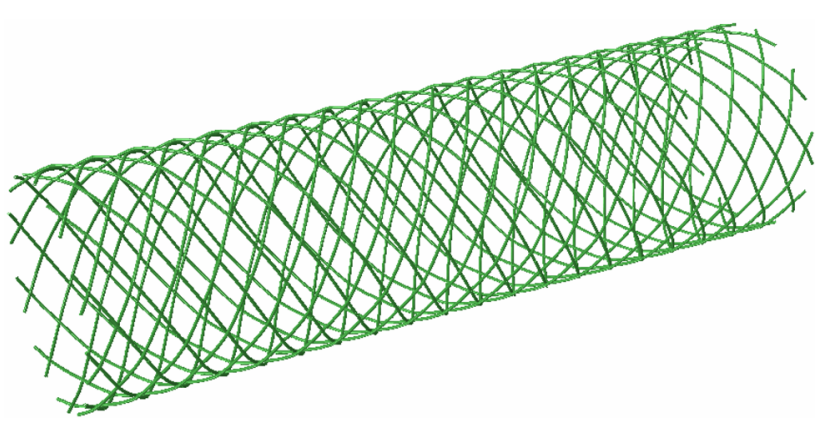

Fig. 1 Solid model of braided wire stent
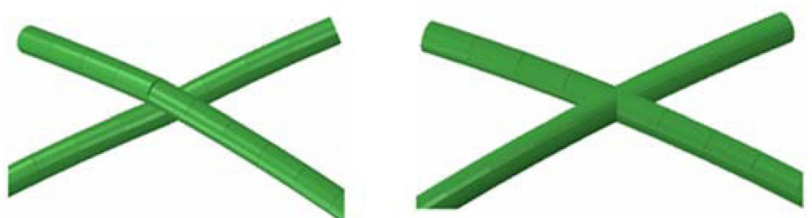

Fig. 2 Stent configurations fabricated with braided wire (left) and corresponding welded wire (right)

The plaque producing $50 \%$ stenosis at the narrowest occlusion, categorized as moderate stenosis, with the length of $30 \mathrm{~mm}$ was attached to the middle of the artery.

The mechanical properties of artery, from a commercial $10 \mathrm{~mm}$ CryoValve $^{\circledR}$ aortic root (CryoLife Inc., Kennesaw, GA, USA), were obtained from uniaxial tensile tests conducted on an uniaxial tensile tester (TestResources Inc., Shakopee, MN, USA) in our laboratory. The reduced polynomial hyperelastic constitutive equation $U=\sum_{i=1}^{N} C_{i 0}\left(I_{1}-3\right)^{i}$ was used to fit experimental data as shown in Fig. 4. The obtained material coefficients $C_{i 0}$ for the artery are $C_{10}=0.0104673 \mathrm{MPa}, C_{20}=0.0194098 \mathrm{MPa}$ and $C_{30}=0.0109830 \mathrm{MPa}$.

A hyperelastic-perfect plastic model was used to describe the mechanical response for plaque as shown in Fig. 4. The corresponding coefficients for the polynomial hyperelastic model were adopted from publication [2] as $C_{10}=0.04 \mathrm{MPa}, C_{02}=0.003 \mathrm{MPa}$, and $C_{03}=0.02976 \mathrm{MPa}$. The plaque plasticity is assumed to initiate at $34 \%$ strain [10]. The material properties of balloon used in post balloon-dilation are assumed as $\mathrm{E}=940 \mathrm{MPa}$ and $\nu=0.4$ [11].

The artery and plaque were all discretized with reducedintegration eight-node linear brick elements (C3D8R), and the numbers of elements are 10,500 and 4200, respectively. The general contact algorithm, which can handle the contact problem between surfaces including element-based surfaces effectively, was applied to the stent wire sliding, as well as stent-artery interface with a friction coefficient of 0.05 [12].

\section{Results}

The stent crimping process led to different behaviors for both the braided and welded wire stents. When the $10 \mathrm{~mm}$ in diameter stent was totally confined by the sheath of $3.4 \mathrm{~mm}$ in diameter, the stent length was increased from original $36 \mathrm{~mm}$ to $70.46 \mathrm{~mm}$ and $65.62 \mathrm{~mm}$ for the braided wire stent and welded wire stent,

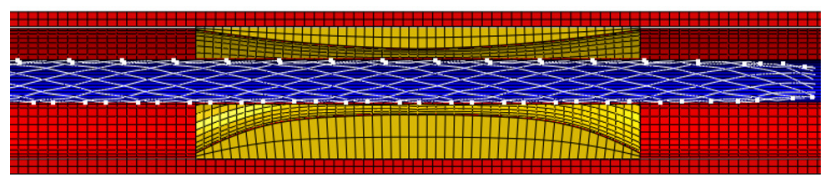

Fig. 3 Crimped braided wire stent in target stenotic artery

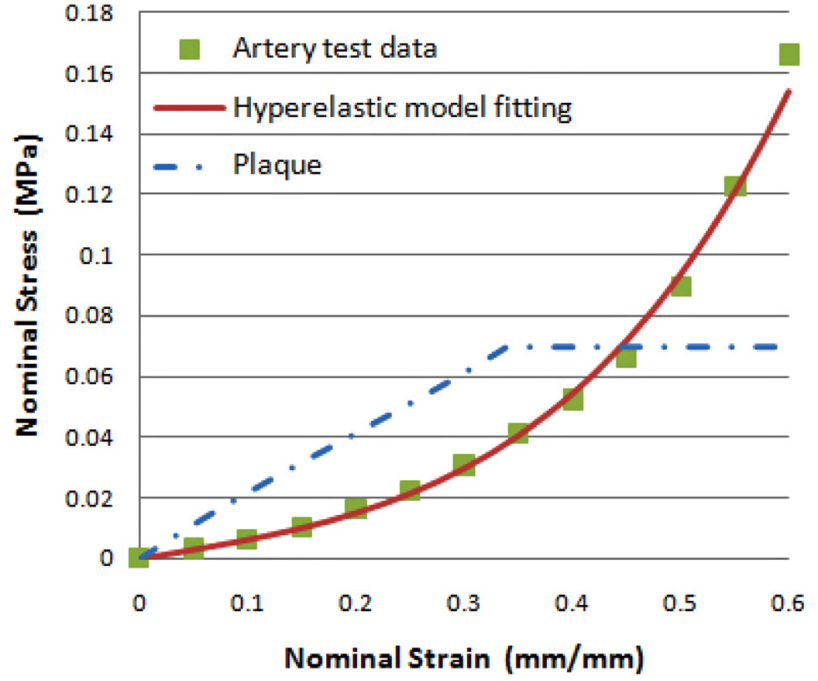

Fig. 4 Stress-strain curves for artery and plaque

respectively. For the braided wire stent, the pitch angle, shown as $\beta$ in Fig. 5, increased to $73.92 \mathrm{deg}$ from its initial value of $30 \mathrm{deg}$, and the corresponding pitch decreased from $1.58 \mathrm{~mm}$ to $0.84 \mathrm{~mm}$. For the welded wire stent, the wire underwent large deformation due to the constraints at the welding spots between crossing wires. Under the same confined diameter, the peak principal logarithm strain on the strut was $0.86 \%$ for welded wire stent, which is $43 \%$ higher than that of the braided wire stent. It is clear that the strain distribution is more uniform for the braided wire stent. The strain energy stored in the welded wire stent is approximately 180 times of the one in the braided wire stent, indicating a higher stiffness for the welded wire stent. When both stents were compressed between two flat plates at the same distance during a stent compression test, the resultant force was $5.713 \mathrm{~N}$ for the welded wire stent and $0.615 \mathrm{~N}$ for the braided wire stent, respectively.

After the crimped stent was delivered to the target lesion and the sheath was pulled away, both stents self-expanded toward their nominal dimensions. For the braided wire stent, the lumen diameter at the narrowest occlusion increased from $4.5 \mathrm{~mm}$ to $4.82 \mathrm{~mm}$, and the corresponding residual stenosis was $46.44 \%$, which did not satisfy the desired residual stenosis standard of $30 \%$ or less [13]. Meanwhile, the deployed stent exhibited a dogbone shape with a diameter of $4.63 \mathrm{~mm}, 9.54 \mathrm{~mm}$ and $9.68 \mathrm{~mm}$ at center, proximal and distal ends, respectively (Fig. 6). The dogboning effect, defined as one minus the ratio of central diameter versus average diameter of two ends, was $51.82 \%$. Poor performance of the braided wire stent in terms of acute lumen gain was consistent with the experimental observation of the Expander ${ }^{\mathrm{TM}}$ stent by Tanaka et al. [14]. It is recommended that a post balloon-dilation

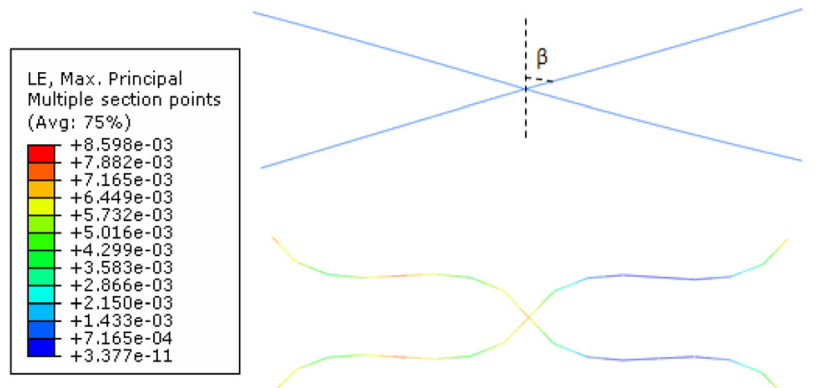

Fig. 5 Principal logarithm strain distributions on one unit of wire stent: braided wire stent (top) and welded wire stent (bottom) 

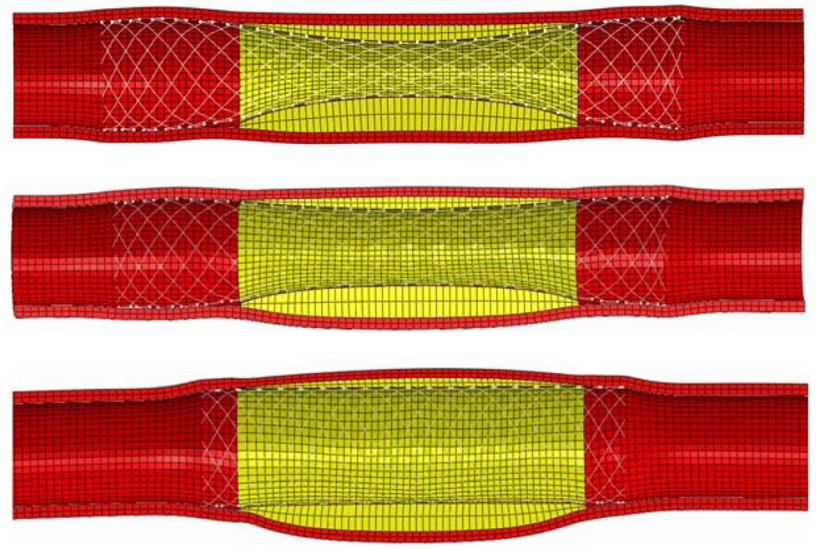

Fig. 6 Performance of wire stents in a stenosed artery: braided wire stent (top), braided wire stent with post balloon-dilation (middle) and welded wire stent (bottom)

is performed to enhance lumen gain and wall apposition. The post balloon-dilation was conducted in our computational model through the insertion of a cylindrical balloon, which is controlled by displacement boundary conditions. It is radially forced to reach the reference dimension of the artery and then unloaded and extracted. The plastic deformation of plaque and the scaffolding support of the braided wire stent led to a final lumen diameter of $6.84 \mathrm{~mm}$, which corresponds to a residual stenosis of $24 \%$. The length of deployed stent was $49.12 \mathrm{~mm}$ compared with its nominal value of $36 \mathrm{~mm}$, and the dogboning effect of the stent after balloon dilation was decreased from $51.82 \%$ to $30.28 \%$.

For the welded wire stent, the acute lumen diameter at the narrowest occlusion increased from $4.50 \mathrm{~mm}$ to $9.94 \mathrm{~mm}$ after its self-expansion, and no residual stenosis occurred. The welded wire stent expanded to a uniform shape and reached the length of $35.32 \mathrm{~mm}$, which is very close to the nominal dimensions. This indicates a high rigidity of the welded wire stent, which is consistent with the observations by Stoeckel et al. [1].

Larger contact pressure between the welded wire stent and underlying tissue was expected. The maximum contact pressure between stent and the underlying tissue is $0.045 \mathrm{MPa}$ for the braided wire stent and $0.065 \mathrm{MPa}$ for the welded wire stent, respectively. The stent-induced peak principal stresses were observed on the central section of the artery which contacts with the thinner side of the plaque as shown in Fig. 7. This may indicate the plaque could serve as a cushion. The peak arterial principal stress is $0.196 \mathrm{MPa}$ for the welded wire stent, while it is only $0.037 \mathrm{MPa}$ for the braided wire stent.

\section{Discussion}

This work examined the effect of fabrication techniques of Nitinol wire stents on their performance in treating a stenosed artery. The behavior of the braided wire stent was studied and compared to a welded wire stent with identical nominal geometry. Before stents were delivered to the target lesion, they need to be confined into a sheath. The crimping process caused distinct behaviors of the stents in terms of changes of length, unit geometry, radial strength and wire stresses. The braided wire stent tends to be longer after crimping than the welded wire stent. The crisscross configuration was maintained for the braided wire stent; however, the pitch angle was increased with a reduced pitch as demonstrated in Fig. 3. The braided fabrication technique allows the relative sliding and rotation between wires, corresponding to the adaptation of pitch and the pitch angle to altered stent geometry. This way the deformation of wire is reduced. On the contrary, the integral configuration of the welded wire stent constrained the wire joints at the cost of large deformation on the wire as shown in Fig. 5. Larger stresses and strains in our welded stent agree with the observation by Zahora et al. [15], which is highly associated with its radial strength and the extent of stent spring back [16]. For the welded wire stent with all junctions welded together, a much higher radial strength was expected, which was predicted by the higher resultant force during a compression test of $5.713 \mathrm{~N}$. This is 9.3 times more than the strength of the braided wire stent. The radial strength of the braided wire stent could be improved by the welded ends [7,17], the number of wires, and the braiding pitch angle [6].

After the deployment of the braided wire stent, an apparent dogbone shape was observed, which might be explained by the non-uniform plaque profile along the longitudinal direction [18], the low stiffness of Nitinol material [3], and the braided structure configurations. This also indicates a good conformity of the stent to the lumen shape, along with the incomplete expansion of the stent and insufficient lumen gain. These shortcomings could be relieved by post balloon-dilation. The welded wire stent exhibits
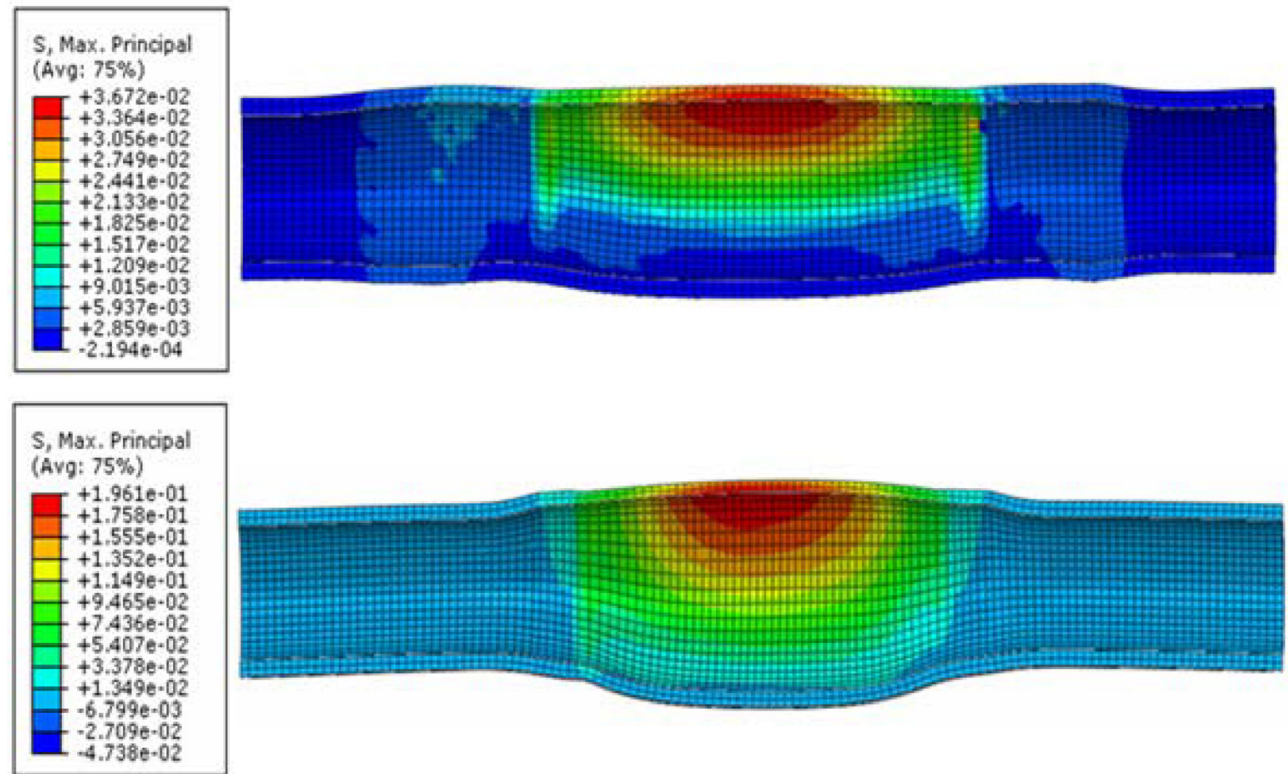

Fig. 7 Stent-induced stress distribution on artery wall: braided wire stent with post balloondilation (top) and welded wire stent (bottom) 
great performance on instant lumen gain and nearly full recovery to its nominal dimension. This implies higher stiffness leading to overstretching of the artery wall especially at the site of narrowest occlusion.

Better performance in terms of lumen gain for the welded wire stent induced more stretching on the artery wall than the braided wire stent and hence resulted in a higher stress level on the artery as shown in Fig. 7. Large arterial stress may trigger neointimal proliferation, and increase the possibility of restenosis [19], but might alleviate stent migration [20]. It is speculated that stent migration is associated with the contact pressure between the tissue and its scaffolding stent [21]; thus, higher contact pressure between the welded wire stent and the underlying tissue might anchor the stent and reduce the possibility of stent migration. On the other hand, such sudden overpressure on the artery during expansion of the welded wire stent might injure the vessel wall [7].

Even though both artery and plaque exhibit inhomogeneous, anisotropic and viscoelastic behaviors [22,23], a homogeneous and isotropic material model is justified for a comparative study between a braided wire stent and a welded wire stent. Perfect plasticity was also used to characterize the behavior of plaque [24]. In spite of these simplifications, this work provides a fundamental understanding of the distinct behaviors of both braided and welded wire stents, and their impact on the stenosed artery.

\section{Acknowledgment}

The authors are grateful for funding from the National Science Foundation under Grant No. 0926880.

\section{References}

[1] Stoeckel, D., Pelton, A., and Duerig, T., 2004, "Self-Expanding Nitinol Stents: Material and Design Considerations," Eur. Radiol., 14(2), pp. 292-301.

[2] Migliavacca, F., Petrini, L., Massarotti, P., Schievano, S., Auricchio, F., and Dubini, G., 2004, "Stainless and Shape Memory Alloy Coronary Stents: A Computational Study on the Interaction with the Vascular Wall," Biomech. Model. Mechanobiol., 2(4), pp. 205-217.

[3] Wu, W., Qi, M., Liu, X. P., Yang, D. Z., and Wang, W. Q., 2007, "Delivery and Release of Nitinol Stent in Carotid Artery and Their Interactions: A Finite Element Analysis," J. Biomech., 40(13), pp. 3034-3040.

[4] Conti, M., Auricchio, F., De Beule, M., and Verhegghe, B., 2009, "Numerical Simulation of Nitinol Peripheral Stents: From Laser-Cutting to Deployment in a Patient Specific Anatomy," Proceedings of the 8th European Symposium on Martensitic Transformations, Prague, Czech Republic.

[5] Rebelo, N., Fu, R., and Lawrenchuk, M., 2009, "Study of a Nitinol Stent Deployed into Anatomically Accurate Artery Geometry and Subjected to Realistic Service Loading," J. Mater. Eng. Perform., 18(5-6), pp. 655-663.
[6] Kim, J. H., Kang, T. J., and Yu, W. R., 2008, "Mechanical Modeling of SelfExpandable Stent Fabricated using Braiding Technology," J. Biomech., 41(15), pp. 3202-3212.

[7] Kim, J. H., Kang, T. J., and Yu, W. R., 2010, "Simulation of Mechanical Behavior of Temperature-Responsive Braided Stents made of Shape Memory Polyurethanes," J. Biomech., 43(4), pp. 632-643.

[8] De Beule, M., Van Cauter, S., Mortier, P., Van Loo, D., Van Impe, R., Verdonck, P., and Verhegghe, B., 2009, "Virtual Optimization of Self-Expandable Braided Wire Stents," Med. Eng. Phys., 31(4), pp. 448-453.

[9] Rebelo, N., Walker, N., and Foadian, H., 2001, "Simulation of Implantable Nitinol Stents," Proceedings of the 2001 Abaqus Users Conference, Providence, Rhode Island, USA.

[10] Gastaldi, D., Morlacchi, S., Nichetti, R., Capelli, C., Dubini, G., Petrini, L., and Migliavacca, F., 2010, "Modelling of the Provisional Side-Branch Stenting Approach for the Treatment of Atherosclerotic Coronary Bifurcations: Effects of Stent Positioning," Biomech. Model. Mechanobiol., 9(5), pp. 551-561.

[11] De Beule, M., Mortier, P., Carlier, S. G., Verhegghe, B., Van Impe, R., and Verdonck, P., 2008, "Realistic Finite Element-Based Stent Design: The Impact of Balloon Folding," J. Biomech., 41(2), pp. 383-389.

[12] Dunn, A. C., Zaveri, T. D., Keselowsky, B. G., and Sawyer, W. G., 2007, "Macroscopic Friction Coefficient Measurements on Living Endothelial Cells," Tribol. Lett., 27(2), pp. 233-238.

[13] Elezi, S., Kastrati, A., Neumann, F. J., Hadamitzky, M., Dirschinger, J., and Schomig, A., 1998, "Vessel Size and Long-Term Outcome after Coronary Stent Placement," Circulation, 98(18), pp. 1875-1880.

[14] Tanaka, N., Martin, J. B., Tokunaga, K., Abe, T., Uchiyama, Y., Hayabuchi, N., Berkefeld, J., and Rufenacht, D. A., 2004, "Conformity of Carotid Stents with Vascular Anatomy: Evaluation in Carotid Models," AJNR Am. J. Neuroradiol., 25(4), pp. 604-607. Available at: http://www.ncbi.nlm.nih.gov/pubmed/15090350.

[15] Zahora, J., Bezrouk, A., and Hanus, J., 2007, "Models of Stents - Comparison and Applications," Physiol. Res., 56 pp. S115-S121. Available at: http://www. ncbi.nlm.nih.gov/pubmed/17552887.

[16] Drexel, M., Selvaduray, G., and Pelton, A., 2007, "The Effects of Cold Work and Heat Treatment on the Properties of Nitinol Wire," Proceedings of the Materials and Processes for Medical Devices Conference, Palm Desert, California, USA.

[17] Stoeckel, D., Bonsignore, C., and Duda, S., 2002, "A Survey of Stent Designs," Minimally Invasive Ther. Allied Technol., 11(4), pp. 137-147.

[18] Kan, H. C., 2010, "Investigation of Plaque Effects on Cardiovascular Stent System," Proceedings of the 4th International Conference on Bioinformatics and Biomedical Engineering (iCBBE), Chengdu, P. R. C.

[19] Timmins, L. H., Meyer, C. A., Moreno, M. R., and Moore, J. E., 2008, "Effects of Stent Design and Atherosclerotic Plaque Composition on Arterial Wall Biomechanics," J. Endovasc. Ther., 15(6), pp. 643-654.

[20] Shi, D., Liao, S. H., and Geng, J. P., 2010, "A Newly Designed Big Cup Nitinol Stent for Gastric Outlet Obstruction," World J. Gastroenterol., 16(33), pp. 4206-4209.

[21] Duerig, T. W., Tolomeo, D. E., and Wholey, M., 2000, "An Overview of Superelastic Stent Design,” Minimally Invasive Ther. Allied Technol., 9(3-4), pp. 235-246.

[22] Weizsacker, H. W., and Pinto, J. G., 1988, "Isotropy and Anisotropy of the Arterial Wall," J. Biomech., 21(6), pp. 477-487.

[23] Gamero, L. G., Armentano, R. L., and Levenson, J., 2002, "Arterial Wall Diameter and Viscoelasticity Variability," Comput. Cardiol., 29, 513-516.

[24] Liang, D. K., Yang, D. Z., Qi, M., and Wang, W. Q., 2005, "Finite Element Analysis of the Implantation of a Balloon-Expandable Stent in a Stenosed Artery," Int. J. Cardiol., 104(3), pp. 314-318. 